\title{
An analysis of the relationship between Sun yat-sen and the independent liberation movement of the Korean nation
}

\author{
PengHuaibin ${ }^{1, a}$ \\ 1 Yanji, jilin, China \\ a bhpeng1971511@qq.com, \\ * PengHuaibin
}

Keywords: Dr. Sun yat-sen. The Korean nation; Independence and liberation; support

\begin{abstract}
Sun yat-sen paid great attention to the independence and liberation of oppressed nations in various Asian countries and regions. On the issue of the independence and liberation of the Korean nation, sun yat-sen showed a completely different attitude from that of the northern warlord government of China at that time, and greatly supported the national independence and liberation movement of the Korean peninsula.
\end{abstract}

\section{试析孙中山与朝鲜民族独立解放运动的关系}

\author{
彭怀涁 ${ }^{1}$ \\ ${ }^{1}$ 延边大学中国近现代史基本问题研究系, 延吉市, 延边州, 吉林, 中国
}

关键词：孙中山; 朝鲜民族;独立解放;支援

中文摘要. 孙中山先生十分关注亚洲各国各地区被压迫民族的独立与解放，在朝鲜民族独立 与解放问题上，孙中山先生表现出与当时中国北洋军阀政府完全不同的态度，对朝鲜半岛的 民族独立解放运动予以了极大地支援。

孙中山先生是近代中国革命的先驱，他不仅以毕生的精力领导中国人民推翻了两千多年 的封建专制统治, 同时也非常关注亚洲其他国家和地区被压迫民族的独立与解放。在朝鲜民 族独立解放运动问题上, 孙中山表现出与当时中国北洋军阀政府截然不同的态度, 非常积极 地支援朝鲜民族的反日独立与民族解放运动。

\section{1.孙中山对朝鲜民族的独立解放进行全方位的支援}

孙中山先生对朝鲜民族解放运动的支援一直伴随着他本人的革命经历而表现在各个领 域。

首先，对朝鲜民族独立解放运动予以舆论上的关注。在日本帝国主义吞并朝鲜后，其领 导的同盟会机关刊物《民报》在对朝鲜丧失独立痛惜的同时, 强烈谴责日本帝国主义的侵略 行径, 为朝鲜独立而急声呼吁, 制造声势; 同时还大力支持中朝两国的进步知识分子组团结 社, 创办发行进步报刊, 大力宣扬朝鲜民族独立解放思想; 他还通过《民报》刊载朝鲜半岛 义兵领袖李麟荣的反日檄文和反日义士安重根击毞日本侵略者伊藤博文的照片，向中国民众 宣传朝鲜人民争取独立解放运动的情况, 分析其斗争实质, 充分表达了中国人民对朝鲜人民 争取民族独立与解放的极大关切与钦佩, 并号召中朝两国民众团结起来, 并肩抗击共同的敌 人。 
1919 年 3 月 1 日，朝鲜半岛爆发争取反日独立的“三・一”运动，随即北京中华民国各界联 合会发表《援助韩人通电》, 指出: “中国对韩国独立有援助之必要, 且有积极援助之义务”, “韩国独立非排日问题，乃生存问题，非韩国一部问题，乃东亚及世界问题。” 4 月 5 日，在 孙中山的影响与指导下, 广东省国民议会通过康基镐等 331 人签名的提案, 并致电北京政府: “韩国问题有世界恒久和平之关系, 韩国问题即人类问题, 韩国问题与中国有绝大关系。满洲、 蒙古、山东、扬子江流域之将来，皆与韩国问题有密接之关系。此重要问题也。”敦促中国 政府和民众认清此问题的实质乃世界和平问题，而非朝鲜一民族之问题，并号召政府和民众 予以大力支援。

其次，对朝鲜民族独立解放运动予以政治上的支持。1921 年 5 月 5 日，孙中山在广州宣 誓就任中华民国非常大总统，拟进行北伐统一中国。同年 10 月，流亡上海的大韩民国临时政 府派申圭植 ${ }^{3}$ 携《国书》前往与护法军政府建立外交关系。《国书》包含五项条款：大韩民国临 时政府承认护法政府为大中华民国的合法政府，尊重其元首与国权; 大中华护法政府承认大 韩民国临时政府; 中华民国军官学校收容与教育韩国学生; 贷款五千万; 许诺租借地, 以培 养韩国独立军。非常大总统孙中山原则上承认这五项条款, 但表示关于第三项须占领武昌之 后实现; 第四项因目前北阀, 财政不富, 很难实现; 第五项因尚未建立正式政府也难以实现。 同年 11 月 18 日，护法军政府举行北伐誓师典礼。非常大总统孙中山在典礼仪式上正式会见 韩国临时政府国使，两国政府正式相互承认。这是韩国临时政府成立以来首次进行的正式国 际性外交关系。此后韩国临时政府为与护法军政府保持经常的外交关系，任命外务部外事局 长朴赞翊为特派交涉员长驻广东，从事与护法政府的外交事务。4

再次，对朝鲜民族独立解放运动予以军事和经济上的援助。1921 年 4 月 17 日，韩国临 时政府在上海法租界挂牌办公。11月 3 日，非常大总统孙中山就韩国临时政府草拟的《中韩 互惠条项》明确表示: 对流亡于中国而继续奋斗之韩国临时政府“自应予以深切同情而加以承 认”，将通令护法军政府所属军校尽量吸收朝鲜族子弟接受军事教育，并一再承诺“北伐计划 完成以后, 届时当以全力援助韩国复国运动。”随后在创办的黄埔军校学员中招收了大量的 朝鲜革命青年入校受训, 同时聘请朝鲜革命者来校任教, 这些朝鲜志士为后来参加朝鲜民族 独立解放运动做出了重大贡献。孙中山还曾命广东中韩协会韩人申圭植组织暗杀队，队员有 一百余名, 曾筹给现洋五万元做该队行装费。并聘任比国人一名, 传习制造炸弹及使用方法。 6在金正明所著《韩国独立运动》一书中曾记载: “韩人赵南升受孙文密派携带巨款来京。”同 时, 韩国独立运动组织在中国境内的募捐活动亦得到孙中山的鼎立支持, 孙中山之子孙科也 曾慷慨解囊。

\section{2.孙中山支援朝鲜半岛独立运动的原因}

首先，孙中山秉承中华民族抑强扶弱的传统思想，视解放包括朝鲜民族在内的一切远东 弱小民族为己任, 在创立兴中会之时, 即发出“收复高（丽）、台（湾）, 巩固中华”的口号， 并作为兴中会进行革命活动的指针。为实现此目标，孙中山曾指出：“中韩两国，同文同种， 本系兄弟之邦, 素有悠久的历史关系, 辅车相依, 唇齿相依, 不可须归分离, 正如西方之英 美。对韩国独立，中国应有援助义务。”

\footnotetext{
1 朴殷植: 《韩国独立运动之血史》, 108 页

2 朴殷植: 《韩国独立运动之血史》, 102-103 页

3 申圭植, 时任韩国临时政府代国务总理兼外务总长、法务总长, 早年曾参加辛亥革命, 组织新亚共济会, 并与中国政界许 多著名人士有深厚交往。

4 《韩国独立运动史》 (三) 第 60-61 页 援引自《关内地区朝鲜人反日独立运动资料汇编》655--656 页

5 闵石麟: 《中国护法军政府承认韩国临时政府始末实纪》 1924 年 7 月 援引自《韩国独立运动与中国》

6 中国第二历史档案馆档案案卷一 $\mathrm{O}$ 二四, 二, 六五号 援引自《关内地区朝鲜人反日独立运动资料汇编》 $1480--1481$ 页

7 闵石麟: 《中韩外交史话》, 重庆东方出版社 1942 年版 $26---27$ 页
} 
其次，孙中山等革命者与朝鲜独立运动领导人之间的战斗友谊是其支援朝鲜民族独立解 放的重要因素。朝鲜独立运动领导人申圭植曾参加过武昌起义, 与孙中山结下战斗友谊, 并 倾其全部资产捐助中国革命。此外，朝鲜志士闵石麟、朴赞翊等也同孙中山及陈其美、宋教 仁等人交情甚笃, 并襄助中国革命。这种战斗友谊使孙中山对朝鲜民族的独立解放也鼎力相 助。

再次，中国革命与朝鲜民族独立运动共同的敌人、共同的使命培育出互相支持、共同合 作的精神。日本帝国主义的侵略和两国封建主义的压迫使进行革命斗争存在共同敌人，于是 孙中山与朝鲜命者逐渐形成反帝反封建的共同使命，他们日益感到互相支持、共同合作的重 要性。孙中山从远东地区的未来与和平，以及亚洲各民族的共同繁荣，尤其是亚洲各弱小民 族的独立解放进行考虑, 指出: “韩国东洋之巴尔干, 此问题解决之前, 永久的和平不能来也。”

最后，孙中山及其所代表的南方护法军政府成立之初在外交上孤立无援，为了打破僵局， 有意支援朝鲜独立运动, 以期打开外交局面, 壮大声威, 为北伐造與论声势。加之军政府地 处南疆，不必惧怕与日本帝国主义正面冲突，同时实现解放东方被压迫民族之理想。

\section{3.孙中山支援朝鲜独立运动的评价}

首先, 孙中山对朝鲜独立解放运动予以了极大的支持, 推动了朝鲜独立解放运动的发展。 但这些支援都是从道义上出发, 是“同情”朝鲜独立的。孙中山从朝鲜亡国的教训中看到中国 若不革命必将会重蹈朝鲜之覆辙, 因此对朝鲜的复国运动抱有深深“同情”之心, 于是秉承中 华之传统，予以了道义上的最大的支持。

其次，由于孙中山所处时代的局限，在领导中国革命是未能提出一个彻底的反帝反封建 的斗争纲领，因此，在支援朝鲜独立问题上亦存在此局限。孙中山多次提出应在承认《马关 条约》基础上有日本承认朝鲜完全“自主”，并指出：“则今日承认韩国之独立，无何等障碍 之生。朝国反因此而表满腔之谢意, 永永不忘矣。中国人对于日本之侵略, 而一扫其一切疑 惑与不安之念。昔日之交情复活, 东洋之平和于兹确立矣。”10把朝鲜独立之希望寄托于日本 之“良心发现”上，显然，以次为基础的朝鲜独立解放是万难实现的。

再次, 孙中山由于自身阶级的局限性, 在进行革命斗争的过程中没有发动广大人民群众, 单凭资产阶级来完成，对待朝鲜独立运动的支援问题上也犯有同样错误，支持朝鲜独立运动 志士之采用简单的革命暴力对反动派的暴力, 而没有发动广大群众, 形成群社会的革命斗争, 必然会走向失败。

总之，孙中山既从朝鲜独立运动中吸取了一定斗争经验，又在道义上对朝鲜独立运动进 行大力支援, 虽然由于时代与阶级的局限存在一定的弱点, 但他们起到的作用是不可估量的, 他开创了当代中朝友谊的先河。

\section{References}

[1] Ami Oh,Byoung-Un Oh. The speciation history of northern- and southern-sourced Eranthis (Ranunculaceae) species on the Korean peninsula and surrounding areas[J]. Ecology and Evolution,2019,9(5).

[2] Jonathan Merritt. The Korean War in Asia: A Hidden History . Edited by Tessa Morris-Suzuki . ( Lanham, MD : Rowman \& Littlefield, 2018 . Pp. x, 226. \$35.00.)[J]. Historian,2019,81(2).

8 闵石麟: 《中韩外交史话》, 重庆东方出版社 1942 年版 $26---27$ 页

9 《新朝青年》第一卷一号 1920 年 3 月 第 65一6 页援引自《关内地区朝鲜人反日独立运动资料汇编》 1477 - 1478 页

10 《新韩青年》第 1 卷 1 号 1920 年 3 月 援引自《关内地区朝鲜人反日独立运动资料汇编》 1477 - 1478 页 
[3] Cho Minjoon,Moon Seoung-Hwan,Lee Ji-Ho,Lee Jae Hyup. Investigation of Comorbidity, Trauma History, and Osteoporotic Fractures in the Postmenopausal Population: A Nationwide, Observational, and Cross-Sectional Study of Korean Orthopedic Outpatient Clinics.[J]. Asian spine journal,2019.

[4] Yu Da Pao,Zhou Wang Ming,Zhou Li,Dai Li Min. [Exploring the history of the management theory and technology of broad-leaved Korean pine (Pinus koraiensis Sieb. et Zucc.)forest in Changbai Mountain Region, Northeast China.][J]. Ying yong sheng tai xue bao $=$ The journal of applied ecology,2019,30(5).

[5] Kim Kwang Seog. Korean Cleft Palate-Craniofacial Association: history and perspectives.[J]. Archives of craniofacial surgery,2019,20(1).

[6] Oh Ami,Oh Byoung-Un. The speciation history of northern- and southern-sourced Eranthis (Ranunculaceae) species on the Korean peninsula and surrounding areas.[J]. Ecology and evolution,2019,9(5).

[7] Suyoung Kim. The Less-Known History of the Voluntary Sector in an East Asian Welfare Regime: A South Korean Case[J]. Nonprofit Policy Forum,2019,10(1). 